\title{
CONSERVAÇÃO VERSUS DESENVOLVIMENTO: UMA ANÁLISE DOS DISCURSOS NO CASO YASUNÍ-ITT
}

\author{
Gabriela Ariane Ribeiro Mendes* \\ Pedro Andrade Matos*
}

\section{RESUMO}

$\mathrm{Na}$ tentativa de solucionar os problemas socioambientais vivenciados pelo avanço da frente petroleira no país, o Equador propôs ao mundo um projeto inovador: renunciar à exploração do petróleo contido no subsolo dos campos Ishpingo Tambococa Tiputini, localizados na porção centro sul da Amazônia equatoriana, em troca de uma compensação financeira da comunidade internacional. Apesar de ter recebido muito apoio de outros Estados e de inúmeras organizações internacionais, a Iniciativa falhou, tendo o então Presidente Rafael Correa anunciado seu fim em maio de 2013. A falha dessa empreitada representa um exemplo claro da insuficiência contida nos discursos de sustentabilidade e cooperação assumidos não só pela comunidade internacional, mas pelo próprio Equador, cujas inconsistências esse artigo se prestou a analisar. Para tanto, utilizou-se dos métodos hipotético-dedutivo e descritivo, com realização de pesquisa bibliográfica.

Palavras-chave: Iniciativa Yasuní-ITT; Equador; petróleo; cooperação; Amazônia.

\section{CONSERVATION VERSUS DEVELOPMENT: AN ANALYSIS OF THE DICOURSES IN THE YASUNÍ-ITT INITIATIVE}

\begin{abstract}
In the attempt to solve the social and environmental problems caused by the advancement of oil exploring companies in the country, Ecuador proposed to the world a very innovative project: renouncing the exploration of the petroleum found under the Ishpingo Tambococa Tiputini fields, located in the south center portion of the ecuatorian amazon, in exchange for financial compensation from the international community. In spite of the support received from other countries and innumerous international organizations, the Initiative failed, having its ending announced in may 2013. The failure of this endeavor represents a clear example of the insufficiency contained in the discourses of sustainability and cooperation assumed not only by the international community, but by Ecuador itself, whose inconsistencies this article has come to analyze. For that, we used the hypothetical-deductive and descriptive methods, with bibliographical research.
\end{abstract}

Keywords: Yasuní-ITT Initiative; Ecuador; Petroleum; cooperation; Amazon.

\footnotetext{
* Mestranda no programa de Pós-Graduação stricto senso em Direito Ambiental da Escola Superior Dom Helder Câmara. Secretária do Grupo de Pesquisa Ambiente, Mineração e Energia nos Tribunais - AMET. Endereço postal: Rua Rio Grande do Norte, 888, apartamento 701, Funcionários, Belo Horizonte/MG, CEP: 30130-131. Endereço eletrônico: gabriela_ariane@hotmail.com. ORCID: https://orcid.org/0000-0002-1015-1182

** Bolsista do Programa Nacional de Pós-Doutorado/CAPES na Escola Superior Dom Helder Câmara/Direito Ambiental e Desenvolvimento Sustentável. Belo Horizonte - MG. Endereço postal: Rua Castelo de Belmonte, 302, apartamento 201, Bairro Castelo, Belo Horizonte/MG, CEP: 31330-080. Endereço eletrônico: matooscv@hotmail.com. ORCID: https://orcid.org/0000-0003-1949-4138.
} 


\section{INTRODUÇÃO}

Ao longo de toda a história, o ser humano se insere no meio ambiente como um agente provocador de mudanças no seu entorno. Com o desenvolvimento de tecnologias e aperfeiçoamento da técnica, essas mudanças foram sendo aceleradas, necessitando para sua consecução de uma quantidade cada vez maior de matéria prima. Associada à apropriação dos bens ambientais houve também um aumento na produção de lixo e poluição.

Todo esse cenário, culminou com uma crise ambiental sem precedentes, cuja consciência somente se aflorou na década de 1970, momento em que houve uma mobilização internacional que, por meio de diversos encontros e convenções pretenderam procurar soluções e formas alternativas de desenvolvimento, organização do espaço e uso do solo. Com elas, visou-se tentar estabelecer uma atuação integrada para promoção da proteção do meio ambiente de forma sistêmica.

A despeito de todos esses esforços, verifica-se que eles não têm sido suficientes. A sociedade de consumo, com sua consequente exploração de recursos não renováveis, produção de resíduos e dispersão de gases efeito estufa na atmosfera, continua a se fortalecer ano a ano, o que faz diminuir as esperanças de que o homem será capaz de reverter os prejuízos ambientais causados pelo seu modo de vida contemporâneo.

Foi nesse contexto que o Equador, país cuja economia é baseada precipuamente na exportação de produtos primários, em especial o petróleo bruto, surgiu com uma proposta ousada e inovadora: renunciar à exploração do petróleo contido no subsolo dos campos Ishpingo Tambococa Tiputini, localizados na porção centro sul da Amazônia equatoriana e que correspondem a $20 \%$ de todas as reservas petrolíferas do país, em troca de uma compensação financeira da comunidade internacional. A Iniciativa, todavia, após três anos de tentativa, falhou. Nesse sentido, o presente artigo se presta ao estudo do insucesso desse projeto, o qual foi denominado "Iniciativa Yasuní-ITT", a partir das ações da comunidade internacional e do governo equatoriano.

Para tanto, foram utilizados os métodos hipotético-dedutivo e descritivo, por meio dos quais se buscou demonstrar, a partir de uma descrição da própria iniciativa e dos movimentos que culminaram em sua origem e desmantelamento, que apesar da busca incessante por um modelo de desenvolvimento sustentável, a sociedade contemporânea ainda 
não se mostrou capaz de renunciar à economia de mercado e à sociedade de consumo em nome da preservação do meio ambiente.

\section{O PARQue YASUní, A INICIATIVA DESTINAdA À SUA PROTEÇÃo E A ECONOMIA EQUATORIANA}

\subsection{As riquezas equatorianas e o Parque Nacional do Yasuní}

O Equador é um país localizado na América do Sul que possui uma superfície de $256.370 \mathrm{~km}^{2}$. Esse valor, que corresponde a somente $0,2 \%$ de todo o planeta (MINISTERIO DEL AMBIENTE DEL ECUADOR, 2010), pode parecer pouco quando comparado à totalidade do território terrestre. No entanto, ele integra um grupo composto por apenas dezessete países que em razão de sua riqueza cultural e biológica são considerados megadiversos. Nesse sentido, pode-se citar que além de possuir a maior quantidade de vertebrados por quilômetro quadrado do mundo, está entre os dez países com maior quantidade absoluta de anfíbios, aves e borboletas (LARREA; WARNARS, 2009).

Essa riqueza natural se dá principalmente em razão de sua localização geográfica privilegiada, que o garante um conjunto de características geológicas, geográficas e climáticas peculiares, dando origem a um espaço com condições ideais para o desenvolvimento de uma vegetação exuberante e de uma rica vida silvestre (MINISTERIO DEL AMBIENTE DEL ECUADOR, 2010).

A megadiversidade do Equador não pode ser atribuída, todavia, considerando-se unicamente essa imensa riqueza natural, devendo-se considerar também sua opulência cultural e humana. Constou-se no último Censo realizado, que cerca de $7 \%$ da população total equatoriana é indígena (INEC, 2010). Ela está compreendida entre 12 diferentes grupos, falantes de 13 distintas línguas (LARREA; WARNARS, 2009), e é em grande parte responsável pela preservação dos ecossistemas nacionais. Esses povos possuem uma relação única com o meio ambiente, de forma que assumem um papel chave na instituição de um novo modelo de desenvolvimento econômico e também na idealização e aplicação de políticas públicas destinadas à adequada proteção ambiental.

Situação distinta não é a encontrada quando se observa o Parque Nacional do Yasuní. Instituído em 1979, ele é localizado na parte oeste da Amazônia equatoriana. Tendo em vista 
sua posição estratégica - próxima não só da linha do equador, mas também das montanhas andinas -, possui um clima quente, com temperatura uniforme e altos índices pluviométricos, conjuntura essa a qual muitos cientistas atribuem sua rica biodiversidade (LARREA; WARNARS, 2009). Estima-se que existem na região mais de 200 espécies de mamíferos, sendo não menos expressivas as espécies encontradas de répteis, anfíbios, aves e insetos. Em apenas $0,25 \mathrm{~km}^{2}$ do parque ${ }^{1}$, é possível encontrar mais espécies arbóreas que as existentes no Canadá e Estados Unidos, somadas. É por essas e outras razões que ele é apelidado de "berçário da Amazônia", sendo considerada uma das áreas de maior biodiversidade do mundo (HADDAD, 2012).

O parque também é casa para diversos grupos étnicos, como os Waorani, Kichwa e Shuar, bem como outros dois que estão em isolamento voluntário, os Tagaeri e Taromenane, que vivem desde 1999 em uma zona considerada intangível (MINISTERIO DEL AMBIENTE DEL ECUADOR, 2010).

A despeito de todo esse tesouro socioambiental que abriga, o parque é alvo de uma exploração predatória de petróleo que ganhou força na década de 1970, da qual já decorreram diversos impactos socioambientais.

\subsection{A economia equatoriana e o surgimento da iniciativa Yasuní-ITT}

Aliada à supracitada opulência socioambiental e cultural, o Equador também possui extensivas reservas de petróleo. Estima-se que as reservas equatorianas comportam a produção de 4.6 bilhões de barris, sendo que 18,3\% delas estão localizadas no campo Ishpingo Tambococa Tiputini (ITT), área que se encontra dentro do Parque Nacional do Yasuní (MINISTERIO DEL AMBIENTE DEL ECUADOR, 2010). A exploração dessas reservas hidrocarboníferas representa atualmente a principal base econômica do país, que apesar de possuir uma matriz relativamente diversificada, ainda é extremamente dependente do extrativismo para obtenção de suas receitas.

A economia equatoriana, a despeito de ter passados por ciclos em que se tentou reverter essa situação, é baseada principalmente na exportação de produtos primários. Inicialmente, o Estado se integrou ao mercado internacional a partir da exportação de cacau para os países europeus, em especial a Inglaterra. Foi a venda de produtos alimentícios a

\footnotetext{
${ }^{1}$ Medida que corresponde a 2,5 hectares.
} 
responsável, por muitos anos, pelo impulsionamento do crescimento econômico do país (ACOSTA, 2005), tendo nos grãos de cacau, e, posteriormente na banana, seus principais protagonistas.

Ainda que em 1930 tenha havido investidas na exploração de petróleo, foi na década 1970 que a extração, exercida principalmente por empresas de capital externo, cresceu de forma exponencial. Enquanto no ano de 1970 o petróleo nem mesmo integrava o rol de produtos com maior protagonismo de exportação - que consistiam em banana, grãos de cacau e café; em 1973 aquele se tornou responsável por 43\% do total das exportações do país, mantendo esse destaque nos anos seguintes, que, apesar das variações naturais do mercado, nunca chegou a totalizar menos de $20 \%$ dos proventos de exportação nacional (OEC, 1970 2016).

Nesse sentido, como acontece com a maior parte dos países de base extrativa não diversificada, o Equador contraiu dívidas externas, que aumentaram exponencialmente com o boom da exploração petroleira, financiado pelo capital internacional. A dívida externa equatoriana teve início ainda na fase da independência, quando a Grã Colômbia, sem apoio de um recém-independente Estados Unidos, precisou adquirir equipamentos militares no exterior para enfrentar seu processo emancipatório. Ao Equador coube, no momento da divisão, assumir uma fração correspondente a $21,5 \%$ do total da dívida, que "transformou-se em um processo pernicioso de renegociações e moratórias" (ACOSTA, 2005, p. 52) que perduram até hoje.

Sobre a matéria, leciona Acosta:

[...] o valor da dívida externa equatoriana cresceu quase 22 vezes entre 1971 e 1981 , passando de 206,8 milhões de dólares no fim de 1971 a 5.868,2 milhões ao concluir o ano de 1981. Essa dívida passou de 16\% do Produto Interno Bruto em 1971 para $42 \%$ em 1981. É preciso dizer que nesse mesmo período o serviço da dívida externa experimentou uma elevação também espetacular: em 1971 comprometia 15 de cada 100 dólares exportados; dez anos depois essa proporção passou a 71\%. (ACOSTA, 2005, p. 116-117).

Associado ao endividamento, a exploração petrolífera trouxe também impactos socioambientais incalculáveis. Um estudo realizado pelo Centro de Direitos Econômicos e Sociais (CESR) em 1994 demonstrou que para operacionalizar a extração houve a abertura de trilhas na floresta e provocação de detonações sísmicas, que geraram erosão e perda de biodiversidade. Constatou também que houve a dispersão de milhares de metros cúbicos de 
lixo tóxico produzido durante a retirada do petróleo, muitas vezes depositado ao ar livre. Além de esse lixo tóxico ter causado problemas de saúde na população da região, a exploração beneficiou apenas um pequeno segmento do povo equatoriano, não tendo a situação econômica do país acompanhado o excepcional crescimento da produção petroleira (THE CENTER FOR ECONOMIC AND SOCIAL RIGHTS, 1994). No mesmo sentido, Bustamante e Jarrín (2004), analisando dados sobre as regiões petroleiras equatorianas, concluíram que os indicadores de infraestrutura e educação nessas zonas são muito inferiores aos indicadores nacionais. Dados esses confirmados pelos estudos de Acosta:

[...] O apogeu do petróleo e o endividamento externo maciço provocaram uma série de transformações. [...] Essas mudanças não afetaram substancialmente as relações sócioeconômicas existentes, nem mudaram os padrões de produção dependentes do exterior. [...] O que é lamentável se considerarmos a grande disponibilidade de divisas existente nos anos 1970, a qual, com uma redistribuição efetiva da riqueza, teria viabilizado a criação de bases sólidas para um desenvolvimento mais autônomo, que teria permitido intervir de forma dinâmica no mercado mundial, sobretudo para a satisfação adequada das necessidades básicas de todos os equatorianos. (ACOSTA, 2005, p. 116-117).

Não menos prejudicadas foram as comunidades locais. Obrigadas a deixar suas terras nativas, e a abandonar suas formas de vida tradicional, essas populações, comumente ignoradas quando da instalação de novos empreendimentos econômicos, buscaram formas de reverter sua desvantagem nos meios de discussão, fortalecendo suas bases para obter a cooperação. Para tanto, com o apoio de organizações nacionais e internacionais que advogavam pelo direito ao meio ambiente ecologicamente equilibrado e reconhecimento dos povos indígenas, agências de desenvolvimento e organizações não governamentais, esses povos constituíram uma forte frente política cuja pressão foi capaz de modificar a forma que a indústria petroleira atuava no país a partir da década de 1990 (SABIN, 1998).

Foi nesse contexto que surgiram as primeiras propostas que posteriormente seriam transformadas na denominada "Iniciativa Yasuní-ITT". Inicialmente, o plano, que surgiu de extensos debates promovidos entre diversos campos da sociedade civil, era o de propor ao mundo uma "moratória petroleira". Nesse sentido, o país se absteria de explorar o petróleo existente na região centro-sul amazônica, preservando toda a sua sociobiodiversidade, e, em troca, desejava a suspensão do pagamento de sua dívida externa. O projeto, oficializado no ano 2000, e apresentado ao Ministério do Meio Ambiente equatoriano em 2003, ganhou força 
política quando incorporado pelo plano de governo 2007-2011 do Movimento Alianza País, encabeçado por Rafael Correa ${ }^{2}$ (ACOSTA; GUIJARRO, 2018).

A proposta assumida pelo governo consistia em renunciar a exploração do petróleo existente nos campos Ishpingo Tambococa Tiputini (ITT), que, conforme supramencionado, abrangem quase $20 \%$ das reservas petrolíferas totais do país, deixando no solo cerca de 840 milhões de barris de óleo bruto. Com isso, pretendia-se proteger não só a imensa biodiversidade da região, mas também resguardar os direitos dos povos indígenas em isolamento, e contribuir para a redução das emissões de gás carbônico na atmosfera.

Em troca dessa renúncia, e utilizando-se do discurso de que os países desenvolvidos devem assumir sua parcela de culpa diante da crise ambiental vivenciada no mundo, condicionaram o sucesso da iniciativa às contribuições da comunidade internacional, que foi chamada a investir no projeto com um valor equivalente à metade dos proventos que seriam resultantes da exploração desses campos. O dinheiro auferido seria então utilizado para investir na diversificação da matriz econômica e energética equatoriana, representando a alavancada do país rumo a uma economia de base não extrativa.

Sobre a proposta, discorrem Acosta e Guijarro:

\begin{abstract}
Na versão do governo se propunha deixar na terra cerca de 840 milhões de barris de petróleo bruto existente nos campos Ishpingo-Tambococha-Tiputini, o qual representaria quase $20 \%$ das reservas petroleiras do país, evitando a emissão de aproximadamente 410 milhões de toneladas de dióxido de carbono. Também se buscava evitar danos ambientais no Parque Nacional Yasuní, uma zona de alta biodiversidade (65 espécies de mamíferos, 110 de anfíbios, 72 de répteis, 630 arbóreas, 280 de cipós, etc.). Mas, sobretudo, respeitaria-se a vida dos povos indígenas em isolamento voluntário que vivem no parque: tagaeri, taromenane e oñamenane. Em troca da não extração o país buscava receber - como compensação do resto do mundo - a metade dos ingressos esperados pela exploração, cerca de 350 milhões de dólares anuais por doze anos (4,2 bilhões de dólares no total). (ACOSTA; GUIJARRO, 2018, p. 142) (tradução nossa) ${ }^{3}$.
\end{abstract}

\footnotetext{
${ }^{2}$ Rafael Correa ganhou as eleições presidenciais do Equador em 2007, tendo sido chefe do Poder Executivo do país entre janeiro de 2007 e maio de 2017. Apesar de sua ascensão ao poder ter sido muito ligada a discursos de proteção do meio ambiente e de populações tradicionais, seu governo foi muito criticado e acusado de politizar essas questões, transformando-as em discursos que não passaram de retóricas.

${ }^{3}$ En la versión del gobierno, se proponía dejar en tierra alrededor de 840 millones de barriles de crudo pesado, existentes en los campos Ishpingo-Tambococha-Tiputini, lo cual representaría casi $20 \%$ de las reservas petroleras del país, evitando la emisión de aproximadamente 410 millones de toneladas de dióxido de carbono. También se buscaba evitar daños ambientales en el parque nacional Yasuní, una zona de alta biodiversidad (65 especies de mamíferos, 110 de anfibios, 72 de reptiles, 630 de aves, 1.130 árboles, 280 de lianas, etc.). Pero, sobre todo, se respetaría la vida de los pueblos indígenas en aislamiento voluntario que viven en el parque: tagaeri, taromenane y oñamenane. A cambio de la no extracción el país buscaba recibir -como compensación del resto del mundo- la mitad de los ingresos esperados de la explotación, alrededor de 350 millones de dólares anuales por doce años (4.200 millones de dólares en total).
} 
A fim de garantir maior credibilidade ao projeto, em 2010 foi estabelecido um fundo fiduciário, gerido por um órgão pertencente ao Programa das Nações Unidas para o Desenvolvimento (PNUD), onde seriam depositados todos os valores recebidos em favor da Iniciativa. As contribuições angariadas se destinariam à implementação do Plano Nacional de Desenvolvimento equatoriano. Assim, os valores se prestariam ao financiamento de medidas que objetivavam a redução do desmatamento; a promoção do reflorestamento, arborização e dos processos de regeneração natural da Terra; o investimento na diversificação da matriz energética nacional, com o desenvolvimento de formas de geração de energia "limpa"; redução das desigualdades sociais; e investimento em pesquisa, ciência, tecnologia e inovação (POZO; CEBALLOS, 2015).

Ademais, o fundo seria governado por um comitê diretivo, composto por seis membros, cada um dotado de poder de voto. Dentre eles estavam três representantes do governo equatoriano, dois representantes de governos investidores, e um representante da sociedade civil equatoriana. Além deles, haveria ainda dois membros vinculados ao PNUD, que apesar de possuírem voz, não possuíam direito ao voto (POZO; CEBALLOS, 2015).

Os recursos poderiam advir tanto de Estados, quanto de organizações civis, empresas privadas e cidadãos comuns. No que tange aos Estados, as contribuições poderiam ser realizadas a partir de doações voluntárias, ou a partir da aquisição de certificados de garantia (Yasuní Guarantee Certificates - YGC) que seriam emitidos pelo governo equatoriano até o limite de 407 milhões de toneladas de $\mathrm{CO}_{2}$ (montante aproximado de dióxido de carbono que, em razão da Iniciativa, deixariam de ser dispersados na atmosfera). O preço desses certificados seria valorado de acordo com as permissões de emissão da União Europeia nos mercados de carbono ${ }^{4}$ (European Union Allowance), e com eles, caso a Iniciativa falhasse, os países poderiam buscar a restituição do montante investido em seu valor nominal (PELLEGRINI et al., 2014).

Apesar disso, a resposta da comunidade internacional não se mostrou satisfatória, de forma que em 2013 o ex-Presidente Rafael Correa anunciou o fim do projeto, e deu início aos procedimentos destinados à exploração do petróleo existente na área. A falha da iniciativa

\footnotetext{
${ }^{4}$ Mecanismo criado no Protocolo de Quito que permite a comercialização das reduções de emissões de gases provocadores de efeito estufa quando devidamente certificadas.
} 
demonstra uma incoerência nos discursos assumidos não só pela comunidade internacional, em especial os países desenvolvidos, mas também do próprio Estado equatoriano.

\section{A POSTURA DA COMUNIDADE INTERNACIONAL E O MEIO AMBIENTE}

Durante os séculos XVI e XVII houve na Europa, especialmente na Inglaterra, o desenvolvimento das primeiras máquinas capazes de substituir o trabalho manual do artesão. Com isso, permitiu-se a montada de linhas de produção de grande escala, que culminaram com a Revolução Industrial ocorrida no século XVIII. O uso dessas máquinas possibilitara não só o surgimento da atual sociedade de consumo, como consolidou a necessidade do uso de energias não renováveis como, por exemplo, o petróleo.

No entanto, foi somente no século XX, após a Segunda Guerra Mundial (final da década de quarenta, e décadas de cinquenta e sessenta), que surgiram as primeiras críticas e movimentos direcionados à proteção ambiental. Nesse sentido, cientistas começaram a estudar os impactos ambientais causados não só pelo aumento na produção de lixo, desmatamento e uso desenfreado dos recursos naturais, mas também os impactos que o lançamento de gazes fruto da queima de combustíveis fósseis (consequências do crescimento econômico), estavam gerando no meio ambiente.

Ainda que tenham havido convenções internacionais destinadas ao debate de problemas ambientais no início daquele século, foi apenas na década de 1970 que a comunidade internacional passou a realmente se atentar para a gravidade dos problemas vivenciados, que, se não tratadas de forma sistêmica, trariam, em não longo prazo, consequências desastrosas à humanidade.

Nessa linha, surge o principal marco para o desenvolvimento da consciência ambiental no mundo: a Conferência das Nações Unidas sobre Meio Ambiente Humano, realizada em Estocolmo (Suécia-1972), que teve por temática o desenvolvimento humano, trazendo à tona uma importante discussão acerca da relação de controle de desenvolvimento versus controle de poluição.

Desde então, reconhecendo-se a necessidade de uma atuação comum de todos os países para solucionar a problemática criada, foram elaborados e adotados diversos documentos internacionais que reconheciam a importância da cooperação global e da necessidade de repartição entre todas as nações das responsabilidades necessárias à promoção 
de uma proteção ambiental eficaz. Foi nesse contexto que surgiu um importante princípio do direito ambiental internacional, o princípio das responsabilidades comunsporém diferenciadas (LIMA, 2009).

Já na Convenção de Estocolmo, apesar de não haver disposições no sentido de responsabilizar e estimular os países desenvolvidos a assumirem uma maior parcela dos "prejuízos" necessários à preservação ambiental, houve a adoção de posturas antagônicas por parte de países do Norte e do Sul, por meio da qual estes já indicavam que viriam posteriormente a exigir que aqueles se encarregassem de maneira mais significativa de iniciativas destinadas à proteção do meio ambiente. $\mathrm{O}$ discurso adotado pelos países em desenvolvimento foi o de que os países desenvolvidos somente chegaram no nível que se encontram em razão da destruição e uso dos recursos ambientais já explorados, inclusive nos territórios dos próprios países hoje considerados em desenvolvimento (PENTINAT, 2004). Dessa forma, além de serem dotados de melhores tecnologias e maiores conhecimentos acerca da gravidade do problema vivenciado, aqueles teriam uma "dívida ecológica" para com estes, que poderia ser compensada a partir de um tratamento diferenciado quando da assunção de compromissos destinados à salvaguarda do meio ambiente; aplicando-se assim a chamada "igualdade material".

Essa responsabilidade diferenciada foi elevada a princípio do direito ambiental internacional na Conferência do Rio de 1992 sobre Meio Ambiente e Desenvolvimento, tendo encontrado previsão em diversos documentos dela oriundos. Nessa toada, o princípio $7^{\circ}$ da Declaração do Rio sobre Meio Ambiente e Desenvolvimento prevê que:

\footnotetext{
Os Estados devem cooperar, em um espírito de parceria global, para a conservação, proteção e restauração da saúde e da integridade do ecossistema terrestre. Considerando as distintas contribuições para a degradação ambiental global, os Estados têm responsabilidades comuns, porém diferenciadas. Os países desenvolvidos reconhecem a responsabilidade que têm na busca internacional do desenvolvimento sustentável, em vista das pressões exercidas por suas sociedades sobre o meio ambiente global e das tecnologias e recursos financeiros que controlam (ORGANIZAÇÃO DAS NAÇÕES UNIDAS, 1992a, p. 155).
}

No mesmo sentido, a Convenção das Nações Unidas sobre a Diversidade Biológica, fruto da mesma Conferência, estabelece, ainda em seu preâmbulo, a necessidade de se preservar o meio ambiente, os ecossistemas e biomas, as populações tradicionais e seus modos de vida, ressaltando-se as condições especiais a que se submetem os países desenvolvidos, os altos investimentos necessários para a preservação da biodiversidade, e a 
importância de sua proteção (ORGANIZAÇÃO DAS NAÇÕES UNIDAS, 1992b). Nessa lógica, estabelece em seu artigo $5^{\circ}$ que

\begin{abstract}
Cada parte contratante deve, na medida do possível, cooperar com outras partes contratantes, diretamente, ou, quando apropriado, por meio das organizações internacionais competentes, em respeito a áreas que superem a jurisdição natural dos estados e em outros assuntos de interesse mútuo, para a conservação e uso sustentável da diversidade biológica. (ORAGANIZAÇÃO DAS NAÇÕES UNIDAS, 1992, p. 5) (tradução nossa) .
\end{abstract}

O princípio pode ser encontrado também em documentos oriundos de outras importantes convenções internacionais, como o Consenso de Monterrey (2002) e no Plano de Ação da Conferência de Johannesburgo (2002).

Naquele, trata-se do problema de financiamento do desenvolvimento, principalmente nos países do sul, e busca-se, por meio das medidas nele contidas, "erradicar a pobreza, alcançar um crescimento econômico sustentável e promover um desenvolvimento sustentável ao tempo que avançamos em direção a um sistema econômico mundial baseado na equidade e que inclua a todos" (ORGANIZAÇÃO DAS NAÇÕES UNIDAS, 2002, p. 2) (tradução nossa $)^{6}$. Frisa, ainda, que mesmo que cada país seja o principal responsável pela a adoção de medidas e políticas que ensejem seu próprio desenvolvimento; é importante lembrar que as economias nacionais se encontram atualmente vinculadas a um mercado global, sendo responsabilidade de comunidade internacional oferecer-se ajuda mútua, a fim de se alcançar os objetivos previstos no consenso.

Conforme se percebe, a Iniciativa Yasuní-ITT apresentava-se como uma proposta, a princípio, segura e eficiente, que coadunava com todos os princípios e postulados pregados por diversos documentos, e defendidos, inclusive, pelos próprios países do Norte em inúmeras conferências internacionais.

É importante ressaltar, também, que no momento em que Rafael Correa apresentou o projeto para a comunidade internacional ele recebeu um enorme encorajamento, não só por órgãos e programas das próprias Nações Unidas, como também pela Organização dos Estados

\footnotetext{
${ }^{5}$ Each Contracting Party shall, as far as possible and as appropriate, cooperate with other Contracting Parties, directly or, where appropriate, through competent international organizations, in respect of areas beyond national jurisdiction and on other matters of mutual interest, for the conservation and sustainable use of biological diversity.

6 "Nuestra meta es erradicar la pobreza, lograr un crecimiento económico sostenido y promover un desarrollo sostenible al tiempo que avanzamos hacia un sistema económico mundial basado en la equidad y que incluya a todos".
} 
Americanos, a Comunidade das Nações Andinas, o Banco de Desenvolvimento da América Latina, a União Europeia, a OPEC, e diversos países como Espanha, Bélgica, Alemanha e França (PELLEGRINI et al., 2014).

A despeito de todo o incentivo recebido, as contribuições para a Iniciativa não lograram em três anos - desde a sua efetiva implementação até o anúncio de seu fim - nem

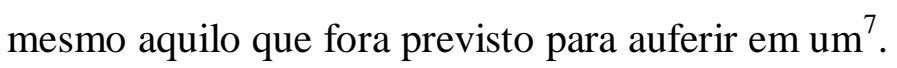

Estudiosos apontam diversos motivos para a ausência de cooperação. As razões vão desde as instabilidades políticas, discursos e posturas adotadas pelo próprio Equador, até conjunturas globais e orgânicas que teriam desencorajado a comunidade internacional a efetivar o apoio conferido à Iniciativa em sua fase de implementação.

Primeiramente, o Equador, assim como grande parte de seus vizinhos latinoamericanos, possui uma história marcada por rupturas político-institucionais e consequentes alterações constitucionais. Isso pode ser constatado pelo próprio fato de que ele teve 19 diferentes constituições desde que se desvencilhou das amarras do colonialismo espanhol (SANTAMARIA, 2011).

Conforme mencionado, Rafael Correa, institucionalizador da Iniciativa, foi eleito em mais um desses momentos, sob a guarida de ambiciosas promessas de ruptura com o neoliberalismo, legitimação das reivindicações dos povos tradicionais marginalizados e proteção ao meio ambiente.

Já em seu primeiro ano de governo promulgou uma nova e emblemática Constituição - conhecida popularmente como Constituição de Montecristi - que foi vista, de início, como uma forma de desvencilhamento de modelos constitucionais importados do Norte global, homogeneizadores, monoculturais e excludentes. O texto representaria, assim, uma nova forma de garantir representatividade a toda a rica gama cultural existente no país, elevando ainda a proteção da natureza a um nível sem precedentes ao dotá-la de direitos próprios.

Apesar dessa postura aparentemente preservacionista, o que se verificou foi que Correa e sua administração, na realidade, nunca se comprometeram a manter e apoiar a Iniciativa independentemente do financiamento internacional, conservando sempre a

\footnotetext{
${ }^{7}$ Entre agosto de 2010 (momento de instituição oficial do fundo) e maio de 2013 (quando Rafael Correa oficialmente declarou o fim da iniciativa) foram prometidos US\$ 221 milhões de dólares à Iniciativa, mas nem todo o valor foi depositado no fundo (PELLEGRINI et al., 2014).
} 
alternativa de exploração (PELLEGRINI et al., 2014) ${ }^{8}$. Essa contradição fez com que com o passar do tempo o governo fosse perdendo o apoio das camadas sociais que o elegeram, culminando, inclusive, com rupturas dentro do seu próprio corpo de ministros, que ao saírem do governo se tornaram oposição.

Dessa forma, o projeto, que já de início não representava um investimento seguro se tratava de um contrato por tempo indeterminado, cujas partes não se manteriam as mesmas ao longo do tempo, podendo, futuramente, inclusive serem eleitos governos de plataforma pró-extrativista no Equador - não conseguiu inspirar, em razões de conjunturas históricopolítico-institucionais internas do próprio país instituidor, confiança na comunidade internacional. Em contratos em que a assimetria de informações e a distância (geográfica e cultural) entre os contratantes é muito exacerbada, a confiança é apontada como um fator essencial ao alcance da cooperação (PELLEGRINI et al., 2014).

A contradição gerada pela postura de Correa, associada a um discurso de culpabilização e responsabilização da comunidade internacional pela destruição de áreas sociobiodiversas no interior do território Equatoriano, culminaram na consolidação de uma visão oportunista da Iniciativa. Autores como Haddad (2012), por exemplo, chegaram, inclusive, a acusar o Equador de tentar obter dinheiro da comunidade internacional a partir do "sequestro" de bens ambientais essenciais ao equilíbrio do planeta, comportamento que a seu ver não deveria ser estimulado sob pena de ser reproduzido por outras nações dotadas das mesmas características - altos níveis de pobreza, ausência de desenvolvimento tecnológico e social, porém com opulenta exuberância natural.

Outro fator determinante foi a forma compensação dos investidores no caso de falha da Iniciativa. Além de eles se desvalorizarem demasiadamente com o decorrer do tempo uma vez que garantem tão somente o ressarcimento de seu valor nominal -, a garantia não se enquadrava em nenhuma das hipóteses de compensação por meio do sistema de emissão de créditos de carbono prevista no Protocolo de Quito, visto que estava baseada no cálculo de “emissões líquidas evitadas", categoria não prevista no referido protocolo (PELLEGRINI et al., 2014).

Por fim, deve-se ressaltar que o setor petroleiro representa a maior fonte de riqueza do governo equatoriano desde a década de setenta, de forma que o retorno econômico da

\footnotetext{
${ }^{8}$ Ainda durante a vigência do Projeto foram iniciados procedimentos destinados ao licenciamento da área para exploração.
} 
exploração, quase que imediato, se mostra muito mais atrativo, sendo também economicamente mais vantajoso que o enfrentamento dos altos custos da preservação. Ademais, é inegável que, se bem sucedida, a empreitada seria exportada e adotada por outros países de características similares ao Equador, tais como Brasil, Bolívia e Venezuela, de forma o seu sucesso ia de encontro aos interesses das transnacionais destinadas a exploração do ouro negro.

Embora não tenham sido encontrados estudos específicos acerca dos impactos das petroleiras no declínio do projeto, já houve outras situações em que o governo Equatoriano tomou decisões prejudiciais aos interesses de suas populações tradicionais e da proteção ambiental, a fim de favorecer os interesses econômicos daquelas ${ }^{9}$.

Todavia, mesmo diante da ausência de apoio internacional, e independentemente dos fatores que levaram ao declínio da proposta, a escolha do caminho da preservação deveria ser lógica ao Equador, principalmente quando considerados seus postulados constitucionais.

\section{A CONSTITUiÇÃo de MONTECRISTI E A ALTERnATIVA AO MODELO DE DESENVOLVIMENTO}

Assim como a Iniciativa Yasuní-ITT, a Constituição do Equador de 2008, apelidada de Constituição de Montecristi, também foi fruto de reinvindicações nascidas no seio da própria sociedade civil equatoriana, e traz em seu bojo um projeto ambicioso e inovador. A Constituição vem com uma proposta revolucionária. Não visa manter o status quo da economia de mercado, mas sim estabelece uma alternativa ao desenvolvimento ${ }^{10}$, diferente de todos os modelos até hoje adotados no mundo, baseado no que denominou-se "economia social e solidária".

A primeira novidade trazida por essa Constituição pode ser encontrada já em seu preâmbulo, que apresenta a necessidade de se construir "uma nova forma de convivência cidadã, em diversidade e harmonia com a natureza, para alcançar o buen vivir, o sumak

\footnotetext{
${ }^{9}$ Foi justamente o que o governo equatoriano foi acusado de fazer a década de 1990 no famoso caso CHEVRON.

${ }^{10}$ Entendido como um processo linear que objetiva o alcance do "progresso", entendido precipuamente como crescimento econômico como seu fim último, ignorando fatores de valorização e crescimento cultural e humano, bem como proteção ambiental.
} 
kawsay" (EQUADOR, 2008) (tradução nossa) ${ }^{11}$. Esses conceitos, advindos das cosmovisões de povos indígenas que integram a população do país, pregam a necessidade de se interpretar as relações entre homem e natureza de maneira holística e integrada, reconhecendo a sua interdependência. Nesse sentido, promove uma alteração do paradigma antropocêntrico regente dessa relação desde a modernidade, que prega uma sobreposição das necessidades humanas aos próprios processos de regeneração da terra, vista como um objeto de exploração e dominação (NETO, LIMA, 2016).

Dessa forma, a fim de garantir o respeito à natureza, ela foi dotada de direitos próprios, previstos entre os artigos 71 e 74 do texto constitucional. Assim, ainda que seja reconhecido o direito dos povos de usar e gozar dos bens naturais, esse usufruto deve ser feito de maneira a respeitar a existência, manutenção e regeneração dos ciclos vitais, estrutura, funções e processos evolutivos naturais (ECUADOR, 2008).

Acosta (2015) defende que o buen vivir representa uma tentativa de ruptura com o “desenvolvimento", conceito que teria sido imposto pelos países do Norte sobre os países do Sul, que tentam desesperadamente alcança-lo, sem sucesso. Dessa forma, ele surge como uma alternativa de organização social e econômica, ainda em construção, baseada nos saberes e vivências indígenas e na valorização de tudo o que é comunitário, garantindo, ainda, a participação e inclusão desses grupos sociais anteriormente excluídos.

Com o intuito de atingir essa proposta de organização social, não voltada ao desenvolvimento linear até então vigente, faz-se necessária a instituição de um novo modelo econômico, ao qual a Constituição de Montecristi denominou em seu artigo 283 de "economia social e solidária”. Segundo Acosta (2015), ele se funda em princípios funcionais, como a solidariedade, a sustentabilidade, a reciprocidade, complementariedade, responsabilidade, integralidade, relacionalidade, suficiência, diversidade cultural, identidade, equidade e democracia.

Esse modelo econômico impõe, então, a construção de um sistema solidário, sustentado sobre bases comunitárias e orientadas pela reciprocidade, e subordinado aos limites que determinam a própria natureza. É um sistema que garante a observância dos ciclos de regeneração da Terra, de forma a não gerar um esgotamento de seus recursos (ACOSTA, 2015).

\footnotetext{
11 "Decidimos construir - una nueva forma de convivencia ciudadana, en diversidad y armonía con la naturaleza, para alcanzar el buen vivir, el sumak kawsay; [...]”.
} 
Apesar desses postulados englobados no próprio texto constitucional equatoriano, o governo Correa, eleito com apoio de diversas organizações de suporte às comunidades tradicionais, sob uma base política que pregava, essencialmente, a alteração da matriz econômica nacional para uma que garantisse sua autossustentabilidade, com proteção dos povos indígenas, seus modos de vida e da imensa biodiversidade nacional, não demorou muito para desistir da Iniciativa Yasuní-ITT e iniciar a exploração dos campos de petróleo nela contidos.

Em um país onde a própria Constituição elenca a natureza como sujeito de direitos, reconhecendo seu valor intrínseco, parece um contrassenso exigir contrapartida financeira para sua conservação. Entretanto, ainda que o Equador tenha optado por chamar a comunidade internacional a assumir sua parcela de responsabilidade na preservação ambiental, bem difuso cuja proteção beneficia a todos de forma indiscriminada, a desistência da inciativa não deveria ter se logrado tão facilmente.

Em que pese essas observações, é necessário ressaltar que a dificuldade em lograr êxito em projetos emancipatórios, aos quais Boaventura de Sousa Santos (2008) denomina de projetos pós-coloniais, não se restringe à comunidade equatoriana. Desde a década de 1980 vêm se fortalecendo no mundo movimentos que pregam a construção de uma nova racionalidade, diretamente vinculada à alteração dos modelos postos de desenvolvimento, que pregam a insuficiência de projetos de sociedade importados/impostos pelo Norte global, que mesmo após a desvinculação político-instituição continuam marcando as estruturas de poder daqueles anteriormente colonizados (SANTOS, 2008).

Todavia, apesar das ideias das populações marginalizadas terem ganhado força nas últimas décadas, a ponto de lograrem reconhecimento constitucional em países como Equador e Bolívia, ainda existe uma dificuldade grande na aplicação prática desses ideais, mormente porque é necessário romper com as estruturas de poder vigentes há tantos séculos.

\section{CONCLUSÃO}

A Iniciativa Yasuní-ITT representou uma tentativa de conciliar interesses e discursos antagônicos entre a conservação do meio ambiente e a exploração de recursos não renováveis. Foi a forma encontrada pela sociedade civil equatoriana, afetada pelo avanço das frentes petroleiras, para implementar os debates que há muito se desenrolavam sobre alternativas ao 
desenvolvimento e redução de desigualdades, de forma a não envolver a exploração predatória daqueles recursos, com violação a direitos de povos indígenas e destruição ambiental.

Apesar de instituída com forte apoio da comunidade internacional, cujas contribuições eram condição sine qua non ao sucesso da empreitada, os investimentos suscitados se mostraram insuficientes; de forma que apenas três anos após sua implementação, o então presidente Rafael Correa anunciou o seu fim.

Essa história de insucesso é uma excelente demonstração de como a sustentabilidade no mundo contemporâneo não passa de um discurso, uma vez que quando chamados a escolher entre preservação ambiental e manutenção da economia de mercado, a última opção é quase sempre a eleita.

Os países desenvolvidos, ainda que tenham reiteradamente assumido compromissos de auxiliar os países em desenvolvimento na preservação de sua biodiversidade, falharam em contribuir com Equador para o sucesso de uma proposta que além de supervisionada pelo próprio Programa das Nações Unidas para o Desenvolvimento, garantia a preservação de uma área com uma sociobiodiversidade única e inigualável.

Por outro lado, o Equador, país cuja Constituição engloba um novo modelo de organização socioeconômica, desvinculado das ideias de desenvolvimento modernamente construídas - que, ao se inserirem em uma economia de mercado, desrespeitam não só a natureza, mas também seus povos -, não se mostrou capaz de renunciar à exploração de petróleo nessa rica região amazônica independentemente de qualquer contrapartida.

\section{REFERÊNCIAS}

ACOSTA, Alberto. Breve história econômica do Equador. IPRI, 2005. Disponível em: http://www.dominiopublico.gov.br/download/texto/al000158.pdf. Acesso em: 29 nov. 2018.

ACOSTA, Alberto. El buen vivir como alternativa al desarollo. Algunas reflexiones económicas y no tan económicas. Política y sociedad, v. 52, n. 2, p. 299-330. Disponível em: https://core.ac.uk/download/pdf/38819863.pdf. Acesso em: 06 dez. 2018.

ACOSTA, Alberto; GUIJARRO, John Cajas. Una década desperdiciada: las sombras del correísmo. Quito: CAAP, 2018.

BUSTAMANTE, Teodoro; JARRÍN, Maria Cristina. Impactos sociales de la actividad petroleira en Ecuador: un analisis de los indicadores. Revista de ciencias sociales, n. 21, p. 
19-34, jan. 2005. Disponível em: http://www.redalyc.org/articulo.oa?id=50902103. Acesso em: 11 jul. 2019.

THE CENTER FOR ECONOMIC AND SOCIAL RIGHTS. Rights Violations in the Ecuatorian Amazon: The Human Consequences of Oil Development. New York, 1994.

INEC - Instituto Nacional de Estadística y censos. Resultados del censo 2010. Ecuador, 2010. Disponível em: http://www.ecuadorencifras.gob.ec/resultados/. Acesso em: 27 nov. 2018.

HADDAD, Ryan. An Un-conventional approach: Ecuador's Yasuní-ITT Initiative is in dicord with the UNFCCC. Sustainable development law \& policy, v. 12, n. 2, p. 15-18, 2012. Disponível em: https://digitalcommons.wcl.american.edu/cgi/viewcontent.cgi?article=1509\&context=sdlp. Acesso em: 28 nov. 2018.

LARREA, Carlos; WARNARS, Lavinia. Ecuador's Yasuní-ITT Iniciative: Avoiding emissions by keeping petroleum underground. Energy for Sustainable Development, v. 13, n. $3,219-223, \quad$ p. 2009. 21sponível em: https://www.sciencedirect.com/science/article/pii/S0973082609000581?via\%3Dihub. Acesso em: 27 nov. 2018.

LIMA, Tatiane Cardozo. O princípio das Responsabilidades comuns mas diferenciadas no Direito Internacional Ambiental. Revista Eletrônica de Direito Internacional, v. 4, p. 160197, 2009. Disponível em: http://centrodireitointernacional.com.br/static/revistaeletronica/volume4/arquivos_pdf/sumari o/art_v4_VI.pdf. Acesso em: 5 dez. 2018.

MINISTERIO DEL AMBIENTE DEL ECUADOR. Reservas de biosfera del Ecuador: lugares excepcionales. Quito: GTZ/GESOREN- DED-WCS- NCI-UNESCO, 2010. Disponível em: http://yasunitransparente.ambiente.gob.ec/documents/348542/351068/Libro+de+RB.pdf/a819 048c-7f89-49fc-a26c-fd289a504d89;jsessionid=L4NvZcUSzhbIO-9GxFY+u791. Acesso em: 26 nov. 2018.

NETO, Joaquim Shiraishi; LIMA, Rosirene Martins. Rights of nature: the "biocentric spin" in the 2008 Constitution of Ecuador. Veredas do Direito, v. 13, n. 25, p. 111-131, jan./abr 2016. Disponível em: http://www.domhelder.edu.br/revista/index.php/veredas/article/view/673/477. Acesso em: 20 mar. 2019.

OEC - THE OBSERATORY OF ECONOMIC COMPLEXITY. What does Ecuador export? 1970-2016. Disponível em: https://atlas.media.mit.edu/en/visualize/tree_map/sitc/export/ecu/all/show/2016/. Acesso em 02 dez. 2018.

ORGANIZAÇÃO DAS NAÇÕES UNIDAS. Declaração do Rio de Janeiro sobre Meio Ambiente e Desenvolvimento, 1992a. Disponível em: http://www.scielo.br/pdf/ea/v6n15/v6n15a13.pdf. Acesso em: 05 dez. 2018. 
ORGANIZAÇÃO DAS NAÇÕES UNIDAS. Convenção das Nações Unidas sobre Diversidade Biológica, 1992b. Disponível em: https://www.cbd.int/doc/legal/cbd-en.pdf. Acesso em: 05 dez. 2018.

ORGANIZAÇÃ̃ DAS NAÇÕES UNIDAS. Aprovação do Consenso de Monterrey, $1^{\circ}$ de março de 2002. Disponível em: http://www.un.org/es/conf/ffd/2002/pdf/ACONF1983.pdf. Acesso em: 05 dez. 2018.

PELLEGRINI, Lorenzo et al. The demise of a new conservation and development policy? Exploring the tensions of the Yasuní ITT iniciative. The extractive Industries and Society, v.1, n. 2, $\quad$ p. 284-291 2014. Disponível em: https://www.sciencedirect.com/science/article/pii/S2214790X14000422?via\%3Dihub. Acesso em: 02 dez. 2018.

PENTINAT, Susana Borràs. Análisis jurídico del principio de responsabilidades comunes, pero diferenciadas. Revista Seqüência, n. 49, p. 158-195, dez. 2004. Disponível em: https://periodicos.ufsc.br/index.php/sequencia/article/view/15227/13847. Acesso em: 05 dez. 2018 .

POZO, Milenka Villca; CEBALLOS, Malka San Lucas. Management and taxation in environmental projects: Ecuador's Yasuní-ITT Iniciative (Yasuní Trust Fund). Revista Catalana de Dret Ambiental, v. 6, n. 1, p. 1-22, 2015. Disponível em: https://www.raco.cat/index.php/rcda/article/view/307095. Acesso em: 04 dez. 2018.

SABIN Paul. Searching for middle ground: native communities and oil extraction in the northern and central ecuatorian amazon, 1967-1993. Environmental History, v. 3, n. 2, p. 144-168, abr. 1998. Disponível em: https://www.jstor.org/stable/3985377?seq=1\#page_scan_tab_contents. Acesso em: 11 jul. 2019.

SANTAMARÍA, Ramiro Ávila. El Neoconstitucionalismo Transformador: El Estado y el Derecho en la Constitución de 2008. Quito: Edic. Abya-Yala, 2011.

SANTOS, Boaventura de Sousa. Do pós-moderno ao pós-colonial. E para além um do outro. Travessias, n. 6/7, p. 15-36, Coimbra, 2008. Disponível em: https://estudogeral.sib.uc.pt/handle/10316/43227. Acesso em: 21 mar. 2019. 